\title{
Insight into Emiliania huxleyi coccospheres by focused ion beam sectioning
}

\author{
R. Hoffmann ${ }^{1,{ }^{*}}$, C. Kirchlechner ${ }^{2,5,{ }^{*}}$, G. Langer ${ }^{3,{ }^{*}}$, A. S. Wochnik ${ }^{4}$, E. Griesshaber ${ }^{1}$, W. W. Schmahl ${ }^{1}$, and C. Scheu ${ }^{2,4}$ \\ ${ }^{1}$ Department of Earth and Environmental Sciences, Ludwig Maximilians Universität (LMU), 80333 Munich, Germany \\ ${ }^{2}$ Max-Planck-Institut für Eisenforschung GmbH, 40237 Düsseldorf, Germany \\ ${ }^{3}$ Department of Earth Sciences, University of Cambridge, Cambridge CB2 3EQ, UK \\ ${ }^{4}$ Department of Chemistry, LMU, 81377 Munich, Germany \\ ${ }^{5}$ Department Material Physics, Montanuniversität Leoben, Austria \\ ${ }^{*}$ These authors contributed equally to this work.
}

Correspondence to: C. Scheu (scheu@mpie.de)

Received: 24 July 2014 - Published in Biogeosciences Discuss.: 2 September 2014

Revised: 29 November 2014 - Accepted: 4 December 2014 - Published: 11 February 2015

\begin{abstract}
Coccospheres of a cultured Emiliania huxleyi clone were sampled in the exponential growth phase and sectioned using a focused ion beam microscope. An average of 69 sections and the corresponding secondary electron micrographs per coccosphere provided detailed information on coccosphere architecture. The coccospheres feature 2-3 layers on average and 20 coccoliths per cell, of which only 15 can be seen in conventional scanning electron micrographs. The outer coccosphere diameter was positively correlated with the number of coccolith layers. By contrast, the inner coccosphere diameter (around $4.36 \mu \mathrm{m}$ ), and hence the cell diameter, was quasi-constant. Coccoliths were not evenly distributed across the coccosphere, resulting more often than not in one part of the coccosphere displaying more coccolith layers than the other. The architectural data allowed for the calculation of the PIC / POC ratio, the density and the sinking velocity of individual cells. The correlation of these parameters has implications for the ongoing debate on the function of coccoliths.
\end{abstract}

\section{Introduction}

In the context of the current climate change debate, understanding ecosystem response to environmental disturbances has become a matter of unprecedented urgency. To predict how ecosystems in general and groups of organisms in particular will respond to ongoing changes such as global warm- ing and ocean acidification, an understanding of past climate changes and the corresponding response of organisms is pivotal (Curey et al., 1951; Gibbs et al., 2013). The marine sedimentary archive potentially provides an enormous database of past organismal responses to climate change (Gerhard and Wefer, 1999). In particular, the calcium carbonate shells of the major pelagic calcifiers - coccolithophores and foraminifera - constitute an archive that extends for tens of millions of years (Bown and Pearson, 2009; Hamilton, 1953). Coccolithophores are surrounded by a sphere (termed coccosphere) of interlocking calcareous platelets, the coccoliths which consist primarily of a radial array of complexly shaped crystals of calcite (Young et al., 1992, 1999; Young and Henriksen, 2003). Both the chemical composition of coccoliths and the morphology of the coccosphere as well as the coccoliths provide information about physiological parameters such as growth and calcification rate at different times in the geological past (Stoll and Schrag, 2000; Gibbs et al., 2013). The morphological analysis of coccospheres and coccoliths relies on scanning electron microscopy (SEM), a tool which renders the accurate determination of size and morphological modification possible (Young and Ziveri, 2000; Langer et al., 2013a). Until now, SEM samples were often prepared by means of conventional sample preparation methods - either smearing coccoliths onto sample holders or using the microtome to create single cross sections through the cells. However, advances in technology now allow us to serially image and section through the coccospheres, opening 
up a whole new way of observing coccosphere architecture. This is important since some features cannot be revealed by classical scanning electron microscopy. The number of coccoliths per cell, for instance, can only be estimated on the basis of the coccoliths that can actually be seen (Langer et al., 2006). The coccolith quota is needed to calculate particulate inorganic carbon (PIC) quota. The inner coccosphere diameter, which equals the cell diameter, can be used to calculate particulate organic carbon (POC) quota. Both coccolith quota and inner coccosphere diameter cannot be determined using conventional SEM, but can be obtained accurately by focused ion beam (FIB) sectioning combined with SEM. The PIC / POC ratio determines whether coccolithophores act as a source or a sink of $\mathrm{CO}_{2}$ relative to the atmosphere (Balch et al., 1991; Holligan et al., 1993; Buitenhuis et al., 1996) and therefore is an important variable for modelling carbon cycling in the oceans (Ridgwell et al., 2009). Moreover, coccolithophore response to climate change is often expressed in terms of PIC and POC quotas. Shedding light on these features and gaining further insight into coccosphere architecture requires step-by-step cross sectioning of complete coccospheres.

A helpful tool to gain information on the interior architecture of samples is FIB-SEM (Inkson et al., 2001; Williams et al., 2005; Uchic et al., 2006; Holzapfel et al., 2007; Kato et al., 2007; Mc Grozther and Munroe, 2007). This combination enables bulk samples to be locally sectioned by means of ion milling and subsequently imaged at high resolution (De Winter et al., 2009). This application of FIB-SEM instruments is commonly referred to as FIB tomography (Inkson et al., 2001; Kubis et al., 2004). Using FIB-SEM tomography to investigate insulators like biological, geological and ceramic samples is challenging because of charging effects that disturb the sectioning as well as the imaging (De Winter et al., 2009). Nevertheless, the FIB-SEM microscope is often used to analyse biological materials which are difficult to cut, such as teeth (Nalla et al., 2005) and bones (Giannuzzi et al., 2007). Another application for FIB-SEM microscopes in biology is the preparation of thin lamellae which can be analysed in a transmission electron microscope (TEM) (De Winter et al., 2009; Schmahl et al., 2008; Kelm et al., 2012). Using backscattered electrons (BSE) instead of secondary electrons (SE) for the image formation allows for discrimination of differently aligned crystals with the same mass contrast due to channelling contrast mechanisms, which depend on the crystallographic orientation of the investigated volume (De Winter et al., 2009).

In the present work, FIB-SEM sectioning and SE as well as BSE imaging were used to study the coccosphere's internal architecture and to determine the coccolith quota of the abundant coccolithophore species Emiliania huxleyi (E. huxleyi). The obtained information was used to calculate the PIC / POC ratio and to estimate the density as well as the sinking velocity of individual coccolithophore cells.

\section{Material and methods}

\subsection{Samples}

Clonal cultures of E. huxleyi type A (strain RCC1238) (Langer et al., 2011) were grown in aged, sterile-filtered $(0.2 \mu \mathrm{m}$ pore-size cellulose-acetate filters) North Sea seawater enriched with $100 \mu \mathrm{mol} \mathrm{L}^{-1}$ nitrate, $6.25 \mu \mathrm{mol} \mathrm{L}^{-1}$ phosphate, trace metals and vitamins as in $f / 2$ medium (Guillard and Ryther, 1962). The strains were obtained from the Roscoff Culture Collection (www.sb-roscoff.fr/Phyto/RCC). The cultures were grown under a 16:8 hour light-dark cycle at a light intensity of $400 \mu \mathrm{mol}$ photons $\mathrm{m}^{-2} \mathrm{~s}^{-1}$ in an adjustable incubator (Rubarth Apparate $\mathrm{GmbH}$, Germany) at $20^{\circ} \mathrm{C}$. Cells were grown in dilute batch cultures, ensuring a quasi-constant seawater carbonate system over the course of the experiment (Langer et al., 2009).

The sample was filtered directly after the collection with a vacuum pump onto an Omnipore polycarbonate membrane filter (diameter: $47 \mathrm{~mm}$; pore size: $0.45 \mu \mathrm{m}$ ), which was dried at $60^{\circ} \mathrm{C}$. The material was then removed with a spatula from the dried filter and dissolved in ethanol. Next the sample was dropped on a silicon wafer and dried. In order to protect the sensitive sample material from electron beam damage and to avoid charging effects, a thin carbon film using a BAL-TEC coating system was deposited.

\subsection{Serial sectioning and imaging}

Serial sectioning was performed with a Zeiss Auriga ${ }^{\circledR}$ crossbeam workstation, using the SEM for imaging and the FIB for cutting roughly $50 \mathrm{~nm}$ thick slices from the coccolithophore samples. The acceleration voltage of the SEM was set to $2 \mathrm{kV}$, and a $30 \mu \mathrm{m}$ aperture was chosen, resulting in a $20 \mathrm{pA}$ imaging current. The Auriga ${ }^{\circledR}$ is equipped with SE, BSE and in-lens detectors, which were used to image the cross-sectional slices at constant contrast and brightness settings.

The FIB gun was operated with $30 \mathrm{kV} \mathrm{Ga}^{+}$ions and a current of $240 \mathrm{pA}$. During the cutting process the FIB gun is inclined by $54^{\circ}$ with respect to the SEM gun and no sample rotation or tilt is required for imaging the cross section of the cut sphere. In order to minimize the ion beam damage, a local electrode was used to avoid charging and drift correction was performed before and after each slice. Drift correction and slice thickness measurement were carried out using a cross-marker in a post-processing step.

\subsection{Carbon quota, density and sinking rate estimates}

The cellular PIC (particulate inorganic carbon) quota was calculated using the following equation (Langer et al., 2009; 
Young and Ziveri, 2000):

$$
\begin{aligned}
& \frac{\text { PIC }[\mathrm{pg}]}{\text { cell }}=n \times m \times \frac{M_{\mathrm{C}}}{M_{\mathrm{CaCO}_{3}}}=n \times \rho \times \frac{M_{\mathrm{C}}}{M_{\mathrm{CaCO}_{3}}} \\
& \times V=n \times \rho \times \frac{M_{\mathrm{C}}}{M_{\mathrm{CaCO}_{3}}} \times k_{\mathrm{s}} \times L^{3} .
\end{aligned}
$$

Here, $n$ is the number of coccoliths per cell (coccosphere); $m$ is the mass of one coccolith; $\frac{M_{\mathrm{C}}}{M_{\mathrm{CaCO}_{3}}}$ is the molar mass ratio of $\mathrm{C}$ and $\mathrm{CaCO}_{3}$, which is equal to $0.12 ; \rho$ is the density of the coccolith; and $V$ is the volume of one coccolith. $V$ can be estimated using the coccolith length $L$ and the shape constant $k_{\mathrm{s}}$ (Young and Ziveri, 2000). To compare our results to those of the literature, we used a coccolith length of $L=3.5 \pm 1.0 \mu \mathrm{m}$ and the E. huxleyi morphotype A shape constant value $k_{\mathrm{s}}=0.020 \pm 0.004$ (Young and Ziveri, 2000). In addition, a density value of $\rho=2.7 \mathrm{pg} \mu \mathrm{m}^{-3}$ was used, which is based on the assumption that the coccoliths are pure calcite (Young and Ziveri, 2000). The parameter $n$, the number of coccoliths per cell, was determined experimentally by using the FIB sectioning.

The cellular POC (particulate organic carbon) quota can be calculated according to the literature as follows (MendenDeuer and Lessard, 2000):

$$
\frac{P O C[\mathrm{pg}]}{\text { cell }}=\mathrm{a} \times V_{\text {cell }}^{b} \text {. }
$$

Here, $V_{\text {cell }}$ is the volume of the cell (protoplast), which is calculated from the inner coccosphere diameter, and $a$ and $b$ are constants which vary depending on the investigated species. For plankton the literature values obtained via $\log -$ $\log$ plots are $b=0.939$ (with a $95 \%$ confidence interval of 0.041 ) and $\log a=-0.665$ (with a $95 \%$ confidence interval of 0.132), resulting in a value of $a=0.216$ (Menden-Deuer and Lessard, 2000). For better comparison with the literature, we have used these values for our calculations. The inner coccosphere diameter was obtained experimentally by using the FIB cross sections.

The overall cell density was calculated from the total cell volume and mass. The total cell volume was estimated using the outer coccosphere diameter. The total cell mass was calculated as follows: the density of the protoplast was assumed to be equal to the density of seawater. Using this assumption and the inner coccosphere diameter, i.e. the maximum protoplast diameter, the mass of the protoplast was calculated. The mass of the coccosphere, i.e. the calcite extracellular matrix mass and the non-calcite extracellular matrix mass, was calculated by using the cellular PIC quota, converted to the cellular calcite quota. The cellular calcite quota divided by the density of calcite yields the volume of the coccosphere occupied by calcite. The volume derived from the outer coccosphere diameter minus the volume derived from the inner coccosphere diameter yields the total coccosphere volume, precisely the volume of the extracellular matrix. The latter minus the volume of the coccosphere occupied by calcite equals the volume of the coccosphere not occupied by calcite. This residual volume was assumed to have the density of seawater. Using the non-calcite coccosphere volume and the density of seawater, the mass of the non-calcite coccosphere volume can be calculated. The total cell mass was therefore the sum of the protoplast mass, the non-calcite extracellular matrix mass and the calcite extracellular matrix mass. The total cell mass divided by the volume derived from the outer coccosphere diameter equals the overall cell density. The sinking velocity was calculated according to Stokes' law (Young, 1994) using the overall cell density, the outer coccosphere radius, the density of seawater $\left(1.024 \mathrm{pg} \mathrm{\mu m}^{-3}\right)$, the dynamic viscosity of seawater $\left(0.00107 \mathrm{~kg} \mathrm{~ms}^{-1}\right)$ and the acceleration due to gravity $\left(9.81 \mathrm{~m} \mathrm{~s}^{-2}\right)$.

\section{Results}

To investigate the 3-D morphology of the coccolithophore species E. huxleyi, serial sectioning in the SEM-FIB was used. SE images acquired at different stages of milling (the video of the whole sequence can be found in the supplementary information) illustrate the complex morphology of E. huxleyi (Fig. 1). Starting from a single complete coccosphere (Fig. 1.1), the individual coccoliths are milled by the $\mathrm{Ga}^{+}$ions (Fig. 1.2). When the interior of the cell is reached, it becomes obvious that the individual coccolith platelets are layered (Fig. 1.3 and 1.4). For the shown example, the layers of coccoliths are uneven (Fig. 1.5 and 1.6); however this is only visible after the middle of the coccosphere is reached. These results imply that the whole coccosphere has to be milled (Fig. 1.7 and 1.8), and it is not sufficient just to mill part of the organism. Our methodology also enables us to visualize the organic residues and intracellular coccoliths within the coccospheres (Fig. 1). However, for a detailed study of the intracellular coccolith, it would be necessary to reduce beam damage of the organic material even further by using, for example, a He source instead of a Ga source in the FIB.

To get reliable information of the coccosphere architecture of a specific strain, it is not sufficient to mill only one sample. Exemplary SE images of six sliced E. huxleyi coccospheres are summarized in Fig. 2. To illustrate the size distribution of the cell cavity, the images used for this figure show the maximum diameter of the cavity. The architecture, i.e. the interlocking of individual coccoliths, as well as the diversity in coccolith layer numbers and the assembly of the coccolith layers can be seen. We found that the coccospheres of our cultured clone are quite heterogeneous. Some have three layers of coccoliths (Fig. 2.2 and 2.4), whilst others have only two (Fig. 2.3). Only one coccosphere was found which had four layers of coccoliths and a smaller inner coccosphere diameter compared to the others (Fig. 2.1). Whether this represents a trend, however, cannot be decided on the basis of a single observation. Most of the coccospheres have an unequal number of layers (Fig. 2.3-2.6), which may correspond 


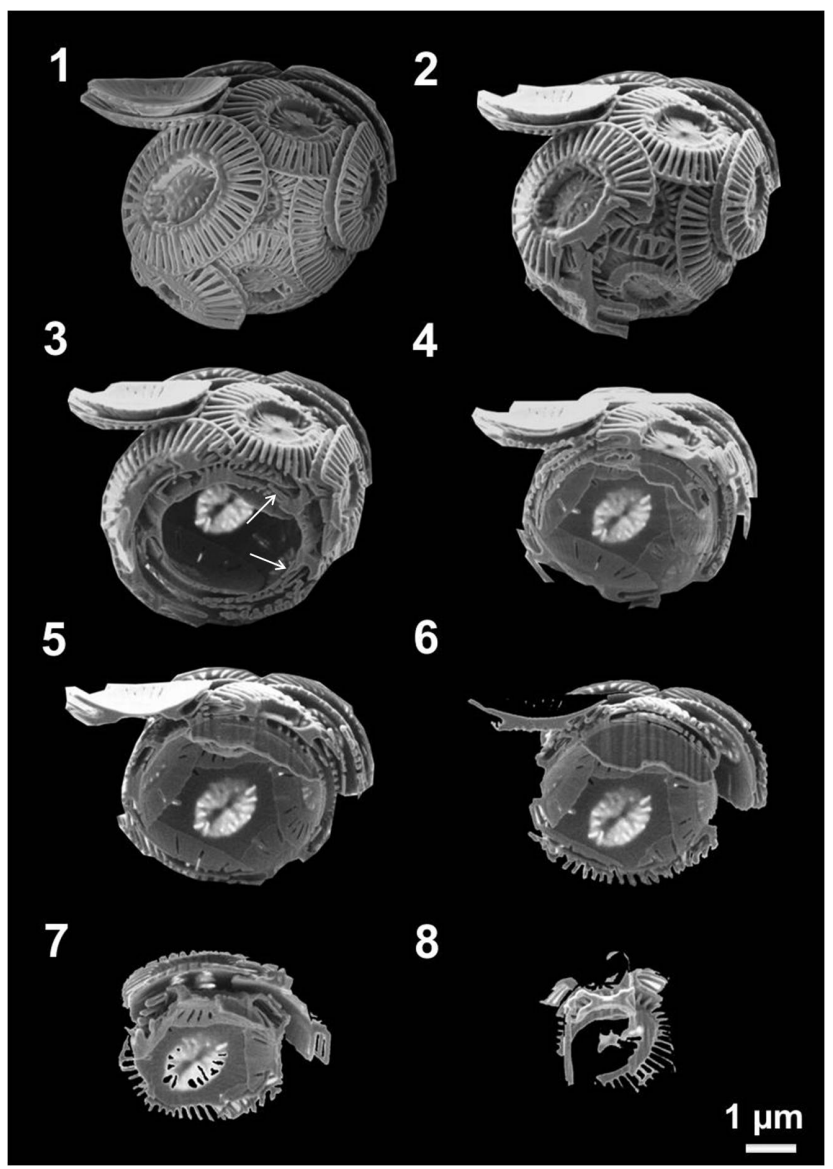

Figure 1. SEM-FIB sectioning sequence of the coccolithophore species E. huxleyi. Image 1 shows the complete coccosphere before slicing, and in 2 the sectioning has just begun. Images 3 and 4 reveal the interlocked layers of coccoliths which make up the coccosphere. The coccosphere is formed by three coccolith layers at the upper region and one in the lower region (5). An organic residue of the coccolithophores cell in the upper area of the sphere is visible in 6 . In 7 and 8 the last steps of the sectioning can be seen.

to the growth direction. Only one out of three coccospheres had coccoliths that were evenly distributed. The FIB-SEM data indicate that the thickness of the coccospheres is related to the coccolith layer number.

The number of coccoliths that make up the sphere were also counted and used for the calculation of the PIC quota. Two different approaches were used to determine the coccolith quota. In one approach only one SEM image was used. Here all visible coccoliths were counted and the coccoliths on the reverse side were estimated. An average of 15 coccoliths were found for the coccospheres containing 2-3 layers. In a second approach the total coccolith number was counted by using the FIB section series. This method showed that the 2-3-layer coccospheres consist of around 20 coccoliths per cell.

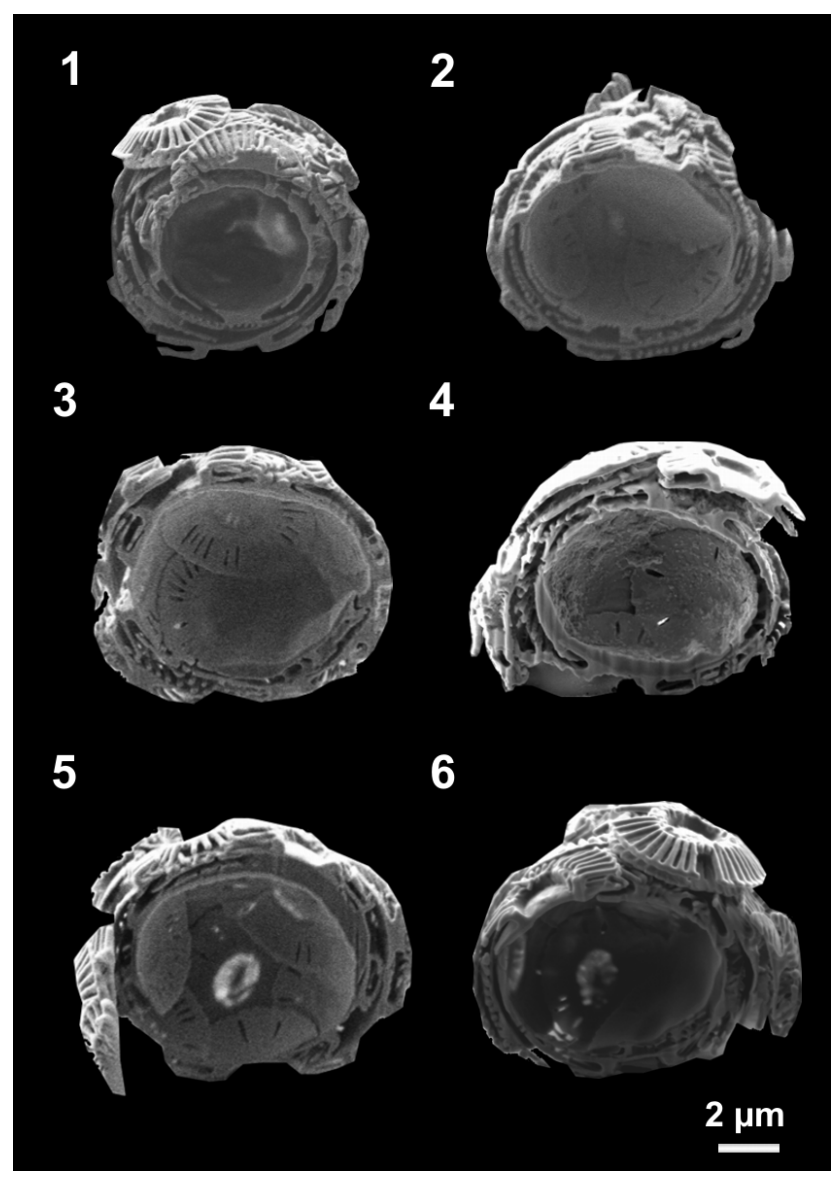

Figure 2. Six exemplary SE images of cross sections through the coccolithophore species E. huxleyi. The coccosphere in image 1 is composed of four coccolith layers and shows the highest shell thickness. In 2 a coccosphere composed of three coccolith layers is given. A coccosphere that indicates that the coccolith layers are not equally spread over the sphere is shown in image 3 and 4 . Images 5 and 6 reveal that the shell thickness of the coccospheres is different depending on the number of coccolith layers.

Serial SEM-FIB sectioning was performed on 27 different E. huxleyi coccolithophores to compare the inner and outer diameters, the number of the coccoliths and layers, and their influence on the shell thickness. The SE images which showed the maximum diameter of the cavity were used to measure the diameter of the outer and inner coccosphere shell. The correlation between inner and outer diameter of the coccosphere shell is given in Fig. 3. The open circles denote the outer diameter and the filled circles the inner sphere diameter, which are plotted in Fig. 3a as a function of the maximum number of layers (in the case of non-equally distributed number of coccoliths). The grey lines correspond to the fitted slope as well as to the calculated 0.9, 0.95 and 0.99 confidence levels. The inner diameter of the coccosphere, which equals the cell diameter, is independent of the maximum number of coccolith layers, while the outer diameter 

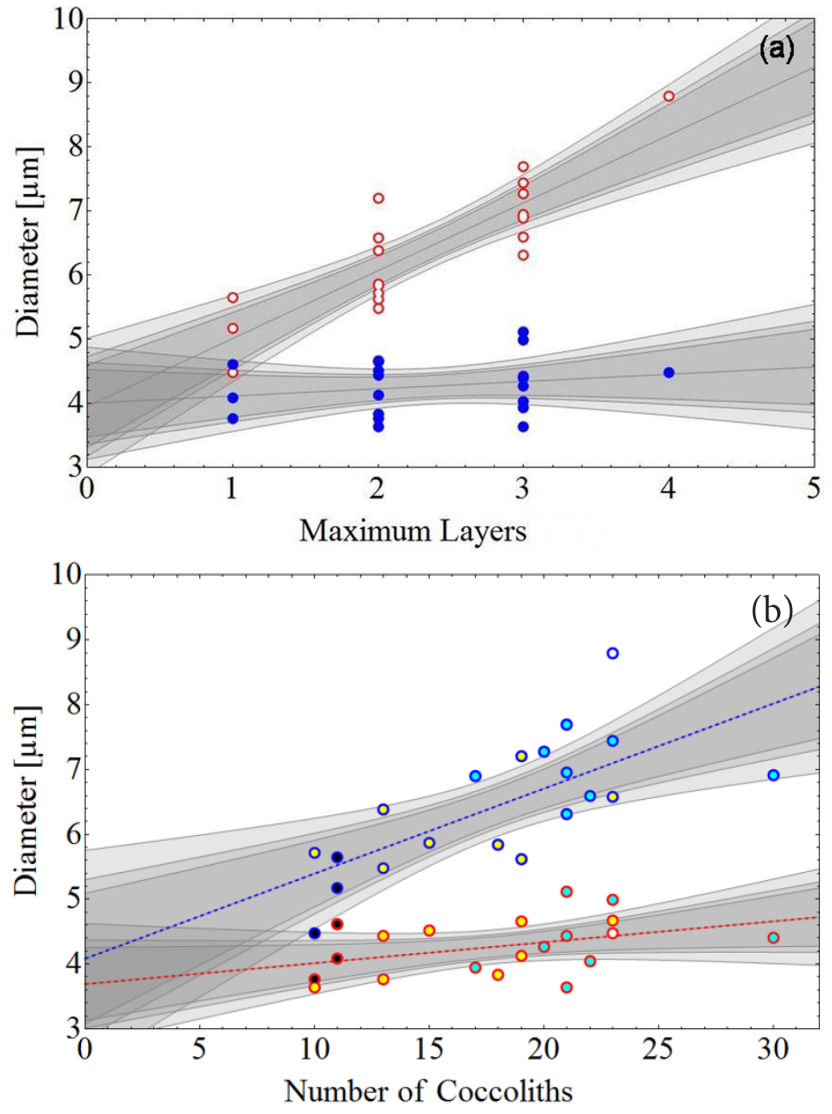

Figure 3. The correlation between inner and outer coccosphere diameter is illustrated. The filled blue circles in (a) show the measured values for the inner diameter, while the open red circle display the data for the outer diameter of the coccosphere. In (b) the dots with a blue shell refer to the outer and the ones with a red shell to the inner coccosphere diameter. The black filling relates to coccospheres with a maximum thickness of one layer, the yellow to those with a maximum of two layers, the blue to those with a maximum of three layers and the white to those with a maximum of four layers. The fitted slopes as well as the calculated 0.9, 0.95 and 0.99 confidence levels are given by the grey lines.

increases linearly with the maximum number of coccolith layers. In addition, in Fig. $3 \mathrm{~b}$ we have plotted the inner and outer diameter of the coccosphere as a function of the number of coccoliths forming this shell. A similar trend can be observed with the inner diameter remaining nearly constant and the outer diameter increasing with increasing number of coccoliths.

Figure 4 shows the relationship between coccosphere thickness (outer-inner diameter) and the number of coccolith layers. As described above, the number of coccolith layers is evenly distributed over the coccosphere in only one of three cases. For the coccospheres where the coccoliths were not evenly distributed, the maximum number of layers was used in the plot. Coccospheres with 1-4 coccolith layers were observed and since most measured points are given for 2-3 lay-
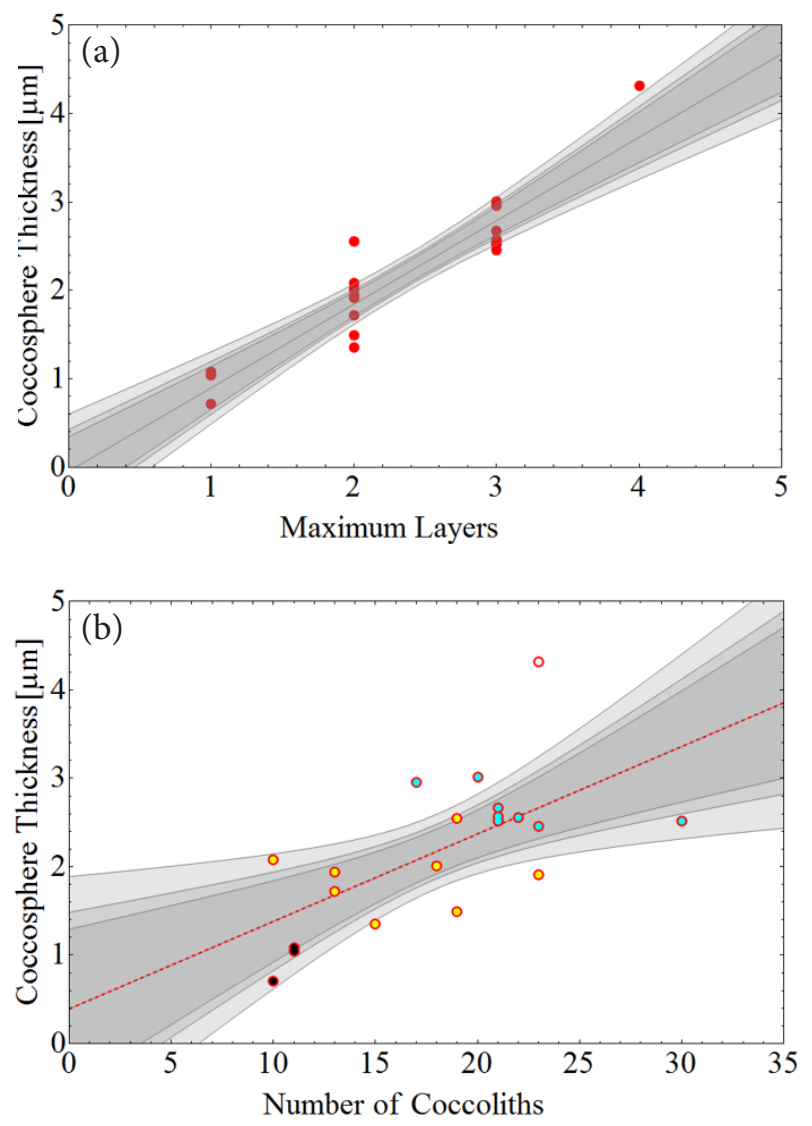

Figure 4. (a) The relationship between the number of coccolith layers which make up the sphere and the thickness of the coccosphere shell is given. A maximum four layers was found in this strain. It can be observed that the thickness increases by approximately $1 \mu \mathrm{m}$ with each coccolith layer. (b) In this plot the thickness is plotted as a function of the number of coccoliths. The black dots refer to coccospheres with a maximum of one layer, the yellow to those with a maximum of two layers, the blue to those with a maximum of three layers and the white to those with a maximum of four layers. The fitted slopes as well as the calculated $0.9,0.95$ and 0.99 confidence levels are given by the grey lines.

ers, the average coccolith layer number for the strain used is 2-3 (Fig. 4). The plot also reveals that the coccosphere thickness increases by about $1 \mu \mathrm{m}$ per coccolith layer (Fig. 4a). The thickness of the coccosphere as a function of the number of coccoliths forming this shell is given in Fig. 4b. It can be seen that the thickness is increasing linearly with increasing number of coccoliths. The fitted slope as well as the confidence level is given by the grey lines.

To gain detailed information on the coccosphere structure, different detectors were used for the imaging. In Fig. 5 a coccosphere cross section imaged using two different imaging methods is shown. An image obtained by a SE detector using the surface near secondary electrons is given in Fig. 5.1. Here the surface topography is illustrated and the SE image gives a three-dimensional impression due to the effect 


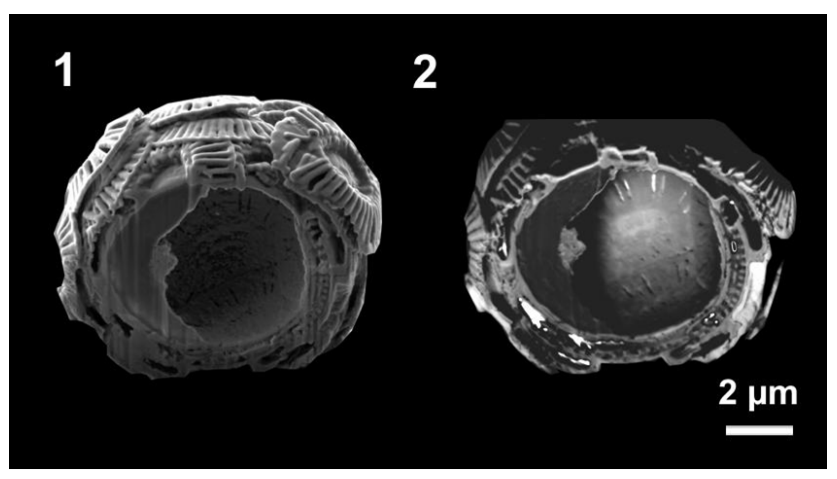

Figure 5. SEM images of the same coccosphere cross section taken using secondary electrons (1) and backscattered electrons (2). Secondary electrons are generated closer to the surface, so image 1 shows a lot more of the finer surface features. Backscattered electrons are sensitive to chemical composition, and are generated deeper in the sample.

that surfaces which are inclined towards the detector appear brighter than surfaces that are turned away (Goodhew et al., 2000). In Fig. 5.2 a BSE in-lens detector was used to create the micrograph. These images reveal information about the element distribution. Light elements like carbon appear darker than elements or materials with a higher atomic number. Due to this so-called material/compositional contrast the organic residue on the left side of the coccosphere appears dark grey (Fig. 5.2). Besides material contrast, channelling contrast can occur in BSE images, which depends on the crystallographic orientation of the investigated volume and allows for differentiating of differently aligned crystals with the same mass-contrast. Thus, the contrast differences of the coccoliths in the BSE image (brighter area at the lower right side of the coccosphere in Fig. 5.2) can be caused by differences in the crystallographic orientation of the calcite crystals and/or by differences in the angle of the exposed face relative to the beam.

\section{Discussion}

In the present study, FIB-SEM sectioning was used to obtain detailed information about the architecture of $E$. huxleyi coccospheres. FIB-SEM sectioning was shown to be appropriate for biological samples for the first time in 1993 (Young et al., 1993). Since this seminal study this method has improved and several groups have reported about the use of FIB-SEM microscopes for material sciences and biological materials (Phaneuf, 1999; Uchic et al., 2006; Giannuzzi et al., 2007; Leser et al., 2009; Grandfield and Engquvist, 2012; Srot et al., 2012). Nevertheless, the investigation of biological and non-conductive materials remains challenging due to the radiation-sensitive nature of these samples and their interaction with the electron and ion beam (Grandfield and Engquvist, 2012). The quality of the imaging is limited by charging effects of the material (Grandfield and Engquvist, 2012). In our study, charging was reduced by depositing a thin carbon film and using a local electrode close to the imaged area. Thus, drift due to charging during the FIB milling as well as SEM imaging was considerably reduced and a continuous drift correction before and after each slice was not necessary. Slice thickness evaluation and drift correction were only performed as a post-processing step using the SE images and a cross-marker. The combination of these methods allowed us to increase the imaging quality and to gain relatively stable FIB section series. Nevertheless, charging effects could not be avoided completely.

In any case, we have shown that FIB-SEM sectioning is an appropriate method for analysing coccosphere architecture in a way which is impossible using conventional SEM. For instance, the number of coccoliths per cell can only be estimated on the basis of conventional scanning electron micrographs, because not all coccoliths can be seen. In an experimental study using Calcidiscus leptoporus the number of visible coccoliths per coccosphere was analysed in this way (Langer et al., 2006). This approach might yield a satisfactory result for Calcidiscus leptoporus, which typically produces one layer of coccoliths only. However, the situation is more complicated in E. huxleyi, because the species does not stop coccolith production upon cessation of cell division (Langer et al., 2013a) or completion of a coccosphere, resulting in multiple layers of coccoliths (Paasche, 2002). These multiple layers can even be seen in exponentially growing cultures such as the one analysed here. We showed that E. huxleyi RCC1238 features 2-3 layers of coccoliths, corresponding to 20 coccoliths per cell. Using the conventional SEM view of a coccosphere, only 15 coccoliths can be seen, which underestimates coccolith quota by $25 \%$.

Another interesting aspect of multi-layer coccospheres is the diameter of the coccosphere. The outer coccosphere diameter was positively correlated with the number of layers (Fig. 3). Our results show that coccospheres composed of 13 coccolith layers have a quasi-constant inner diameter of about $4.36 \mu \mathrm{m}$ (Fig. 3).

Since the cell diameter is positively correlated with the POC quota (Menden-Deuer and Lessard, 2000), the inner sphere diameter can be used to estimate POC quota. The corresponding PIC quota can be estimated using coccoliths per sphere and converting the coccolith size to mass (Young and Ziveri, 2000). Hence, these data render it possible to estimate the PIC / POC ratio of individual cells. We calculated a cellular POC quota of 7.2(standard deviation (SD) 2.1) $\mathrm{pg} \mathrm{cell}^{-1}$ and a PIC quota of 5(SD 1.5) pg cell ${ }^{-1}$. Both the POC and the PIC quota are lower than values determined on bulk samples using elemental analysis via dynamical flash combustion (Langer et al., 2009). The difference between our estimates and the data in Langer et al. (2009), however, is very small considering the two radically different approaches used to determine carbon quotas. First, we used a small sample of individual cells as opposed to an average of millions of cells. 

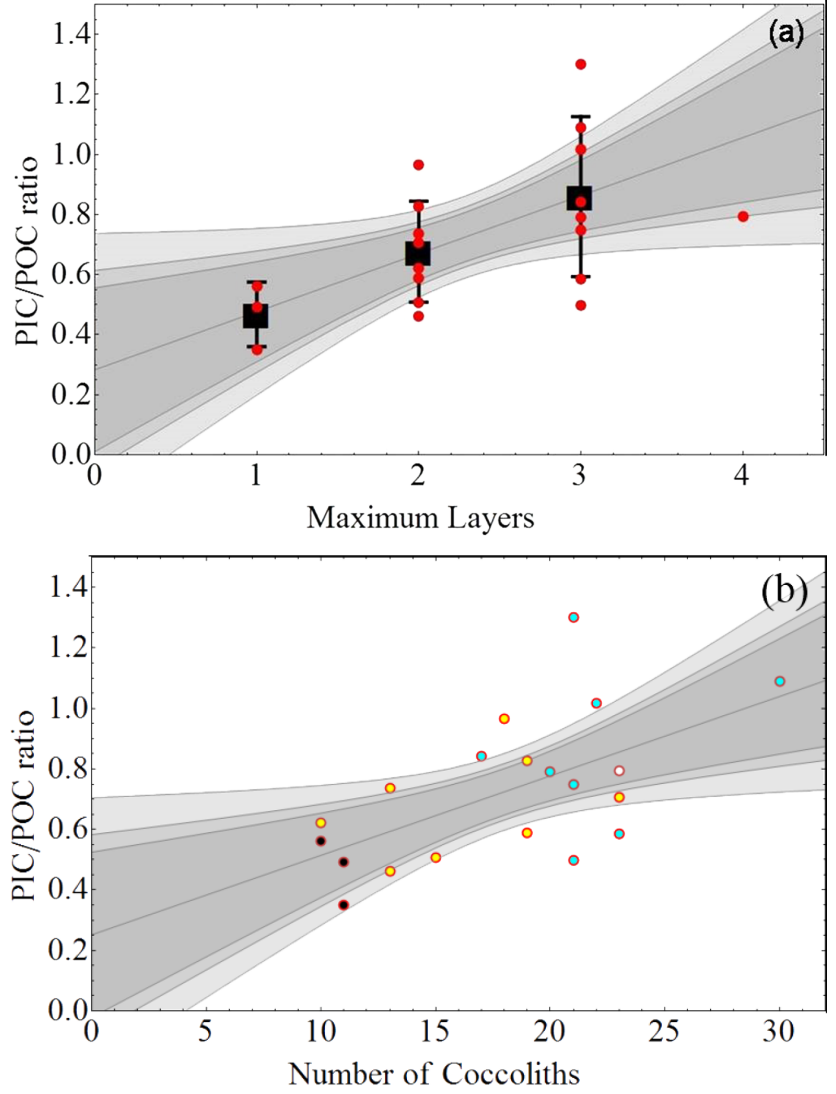

Figure 6. The calculated PIC / POC ratio as a function of (a) maximum layer of coccoliths and (b) number of coccoliths is given. In (b) the black dots refer to coccospheres with a maximum of one layer, the yellow to those with a maximum of two layers, the blue to those with a maximum of three layers and the white to those with a maximum of four layers. The fitted slopes as well as the calculated $0.9,0.95$ and 0.99 confidence levels are given by the grey lines.

Second, our estimates are based on standardized conversion factors, which might not be perfectly suited for this particular set of samples. Third, our raw data are biometrical as opposed to the chemical-analytical raw data on which the Langer et al. (2009) data set is based. The PIC / POC ratio estimated here, i.e. 0.72 (SD 0.24), falls within the range of values reported in Langer et al. (2009). The high, by comparison with data in Langer et al. (2009), standard deviation of 0.24 reflects the fact that we picked a small number of cells comprising a considerable range with respect to number of coccolith layers or number of coccoliths (Fig. 6). Despite the large scatter in the data, a clear positive correlation between the PIC / POC ratio and the number of coccoliths and coccolith layers occurs (Fig. 6).

At first glance this suggests that a higher PIC / POC ratio entails a higher overall density of the cell (Benner, 2008). This assumption is important in the ongoing debate on the question of nutrient limitation of coccolithophores in particular and the function of coccoliths in general. It has been
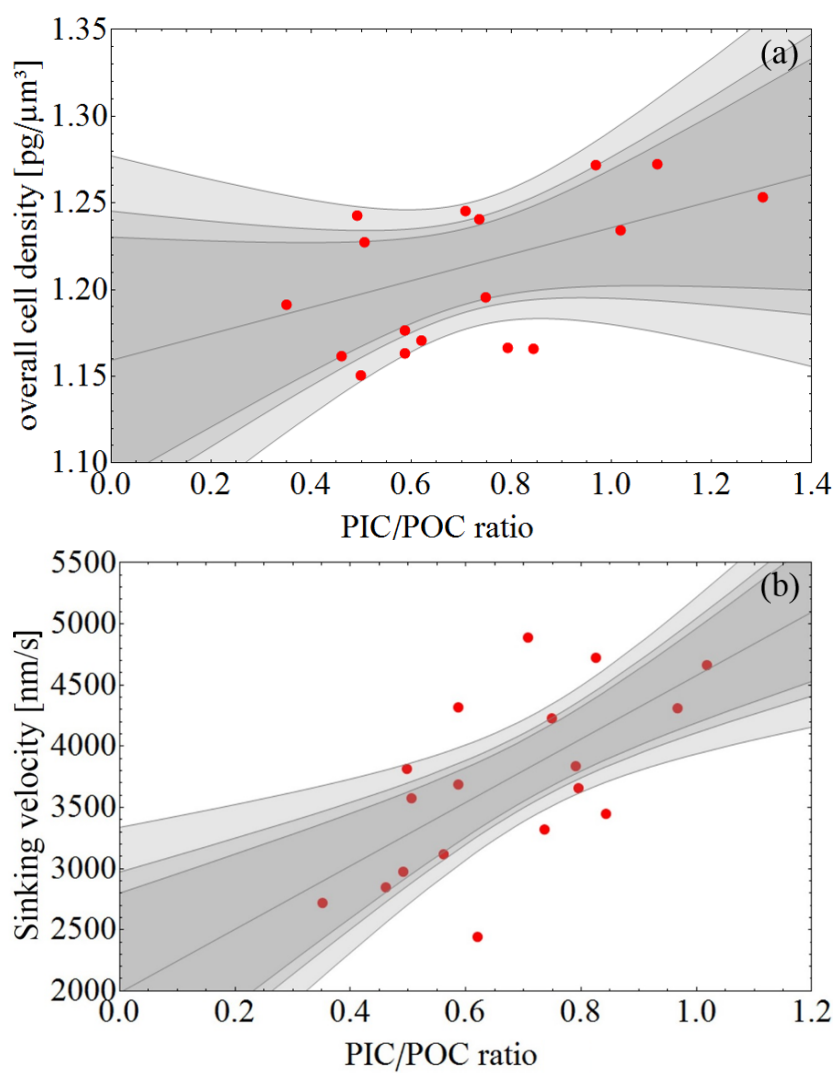

Figure 7. The overall cell density as function of the PIC / POC ratio is plotted in (a). The black line illustrates a linear trend that was assumed in the literature (Paasche, 1998). The linear regression is described by: density $=0.08 \times(\mathrm{PIC} / \mathrm{POC})+1.16\left(r^{2}=0.10\right)$. In $(\mathbf{b})$ the sinking velocity is plotted as a function of the PIC / POC ratio. The fitted slopes as well as the calculated $0.9,0.95$ and 0.99 confidence levels are given by the grey lines. The linear regression is described by: sinking rate $=2593 \times(\mathrm{PIC} / \mathrm{POC})+1986\left(r^{2}=0.50\right)$

proposed that coccoliths may have a ballasting function by increasing the cell's density (Young, 1994). A widely held, but by no means uncontested (Langer et al., 2012; Langer et al., 2013b), notion is that nutrient limitation leads to increased calcification rate, which in turn leads to a higher overall cell density and thus increased sinking rate (Baumann et al., 1978). Indeed, several studies have shown an increase in E. huxleyi's PIC / POC ratio due to nutrient limitation regardless of the calcification rate (Paasche, 1998). Our data set renders it possible to test the hypothesis that an increase in the PIC / POC ratio entails an increase in overall cell density and therefore sinking rate (Benner, 2008).

The overall cell density and the sinking velocity are plotted as a function of the PIC / POC ratios in Fig. 7. While the sinking velocity is linearly increasing with increasing PIC / POC ratio, there is no good correlation between overall cell density and the PIC / POC ratio. Hence, a change in PIC / POC ratio alone is not sufficient to infer a change in overall cell density. While this might seem counter-intuitive, 
it reflects the fact that cell architecture plays an important role in defining overall cell density. This role of cell architecture has, understandably, been overlooked so far.

In the context of a standard culture experiment, the number of analyses required is at least an order of magnitude greater than the one performed in the present study. This is far too time-consuming for the scope of a standard culture experiment, which usually focuses on other parameters such as organic carbon production. However, density and sinking rate estimates might alternatively be based on light microscopy data (Gibbs et al., 2013), which are easier to obtain than FIBSEM data. It would be worthwhile to perform a comparative study to figure out whether densities and sinking velocities based on light microscopy agree with those based on FIBSEM data. The fossil material used by Gibbs et al. (2013) would in fact be ideal for further studies, because it features, quite unusually, many complete coccospheres. Thus this material would additionally render it possible to apply the FIBSEM method to fossil material. PIC and POC quotas as well as overall cell density and sinking rate are a very interesting amendment to the data presented by Gibbs et al. (2013), because the authors showed that Coccolithus displays peakPETM-specific (Paleocene-Eocene Thermal Maximum) cell geometry, namely higher coccolith quota and bigger coccospheres. PIC / POC ratios would allow for assessing this important calcifier's feedback on carbon cycling over the PETM, the closest geological approximation to current climate change. Sinking rates give insights into the nutrientlimitation-sinking-rate debate (Baumann et al., 1978), because nutrient availability during the PETM was presumably considerably altered (Gibbs et al., 2013).

Our measurements have indicated that the overall cell density is not a linear function of the PIC / POC ratio but instead the data are scattering around a nearly constant value (Fig. 7a). In contrast, the sinking velocity is increasing linearly with increasing PIC / POC ratio (Fig. 7b). The reason for this is that Stokes' law, which was used to calculate the sinking rate, features not only particle density but also particle diameter. Hence only the combination of the latter two parameters allows for statements to be made about the sinking rate. Therefore it seems as if the PIC / POC ratio is a poor indicator of density, but possibly a useful one of sinking rate. That would vindicate the conclusion, if not the reasoning, of Benner (2008).

Is the method of estimating density employed here accurate enough? We argue that it is. First, the values calculated here agree well with the ones calculated by Bach et al. (2012) based on a fundamentally different approach. Second, the assumptions made here are reasonable. Most marine phytoplankton cells have, indeed, a protoplast density which equals that of seawater (Boyd and Gradmann, 2002). Moreover it is reasonable to assume that the non-calcite space in the coccosphere (i.e. the extracellular matrix) has the density of seawater, because it actually is seawater in a polysaccharide matrix, and even if the polysaccharides present (Henrik- sen et al., 2004) should lower the density, this would only affect the absolute value of overall cell density and not the relationship of overall cell density and the PIC / POC ratio (Fig. 7a). In summary, our cell-architecture-based approach allows us to estimate, with sufficient accuracy, the overall density of an individual coccolithophore cell. Taken together with individual cell PIC / POC ratios, this sheds new light on the old question of the relationship between coccolithophore nutrient limitation and sinking rates.

\section{Conclusions}

In the present work we studied the shells of E. huxleyi by using a combination of FIB sectioning and SEM imaging. We showed that the combination of a thin carbon film coating and drift correction by using a cross-marker in a postprocessing step is a useful method to reduce charging effects and drift when imaging $E$. huxleyi coccospheres by means of FIB-SEM. By using this preparation and imaging technique we were able to get information about the inner assembly of E. huxleyi coccospheres. The culture (strain RCC1238) studied here was found to consist of 2-3 coccolith layers and an average number of 20 coccoliths per cell. The cell cavity for these coccospheres shows a constant diameter of about $4.36 \mu \mathrm{m}$. It was demonstrated that FIB sectioning is a useful tool to elucidate coccosphere architecture, rendering accurate determination of cellular coccolith quota and estimates of single-cell PIC / POC ratio, density and sinking rate possible.

Author contributions. All authors contributed to the study and gave their approval of the final version of the manuscript. R. Hoffmann designed and partly performed the experiments, carried out quantitative analysis and wrote the main parts of the manuscript. C. Kirchlechner established imaging and milling conditions and performed the experiments together with R. Hoffmann. G. Langer cultured Emiliania huxleyi; calculated PIC, POC, density and sinking rate; interpreted the data; and wrote the respective parts of all sections. A. S. Wochnik was involved in the quantitative analysis and manuscript writing. E. Griesshaber and W. W. Schmahl were involved in discussions. C. Scheu initiated the experiments and was involved in analysis, discussion and writing of the manuscript.

Acknowledgements. Special thanks go to Jeremy Young, whose thoughtful comments helped us to improve the manuscript considerably. We are grateful for the funding received from the German Science Foundation (DFG grant no. SCHM 930/15-1). R. Hoffmann thanks the Bayerische Eliteförderung (BayEFG) for a fellowship. This work was funded in part by the European Research Council (ERC grant 2010-NEWLOG ADG-267931 HE). We thank I. Druckenmüller for her assistance in this project.

Edited by: J. Middelburg 


\section{References}

Balch, W. M., Holligan, P. M., Ackleson, S. G., and Voss, K. J.: Biological and optical properties of mesoscale coccolithophore blooms in the Gulf of Maine. Limnol. Oceanogr., 36, 629-43, 1991.

Baumann, G. F., Isenberg, H. D., and Gennaro, J. J.: The Inverse Relationship Between Nutrient Nitrogen Concentration and Coccolith Calcification in Cultures of the Coccolithophorid $\mathrm{Hy}$ menomonas sp., J. Protozool., 25, 253-6, 1978.

Benner, I.: The utilization of organic nutrients in marine phytoplankton with emphasis on coccolithophores, Universität Bremen, Dissertation, 2008.

Bown, P. and Pearson, P.: Calcareous plankton evolution and the Paleocene/Eocene thermal maximum event: New evidence from Tanzania, Mar. Micropaleontol., 71, 60-70, 2009.

Boyd, C. M. and Gradmann, D.: Impact of osmolytes on buoyancy of marine phytoplankton, Mar. Biol., 141, 605-18, 2002.

Buitenhuis, E., van Bleijswijk, J., Bakker, D., and Veldhuis, M.: Trends in inorganic and organic carbon in a bloom of Emiliania huxleyi in the North Sea, Mar. Ecol. Prog. Ser., 143, 271-82, 1996.

Curey, H., Lowenstam, H. A., Epstein, S., and McKinney, C. R.: Measurement of Paleotemperatures and Temperatures of the Upper Cretaceous of England, Denmark, and the Southeastern United States, Geol. Soc. Am. Bull., 62, 399-416, 1951.

De Winter, M. D. A., Schneijdenberg, C. T. W. M., Lebbink, M. N., Lich, B., Verkleij, A. J., Drury, M. R., and Humbel, B. M.: Tomography of insulating biological and geological materials using focused ion beam (FIB) sectioning and low-kV BSE imaging, J. Microsc., 233, 372-83, 2009.

Gerhard, F. and Wefer, G.: Use of Proxies in Paleoceanography. Examples from the South Atlantic. Berlin, Heidelberg, SpringerVerlag, 1999.

Giannuzzi, L. A., Phifer, D., Giannuzzi, N. J., and Capuano, M. J.: Two-dimensional and 3-dimensional analysis of bone/dental implant interfaces with the use of focused ion beam and electron microscopy, J. Oral. Maxillofac. Surg., 65, 737-47, 2007.

Gibbs, S. J., Poulton, A. J., Bown, P. R., Daniels, C. J., Hopkins, J., Young, J. R., Jones, H. L., Thiemann, G. J., O’Dea, S. A., and Newsam, C.: Species-specific growth response of coccolithophores to Palaeocene-Eocene environmental change, Nat. Geosci., 6, 218-22, 2013.

Goodhew, P. J., Humphreys, J. F., and Beanland, R.: Electron Microscopy and Analysis, 3rd Edn., London, New York, Taylor and Francis, 2001.

Grandfield, K. and Engqvist, H.: Focused Ion Beam in the Study of Biomaterials and Biological Matter, Adv. Mater Sci. Eng., 1-6, 2012.

Guillard, R. R. L. and Ryther, J. H.: Studies of marine planktonic diatoms, I, Cyclotella nanna (Hustedt) and Detonula convervacea (Cleve), Can. J. Microbiol., 8, 229-39, 1962.

Hamilton, E. L.: Upper Cretaceous, Tertiary, and Recent planktonic Foraminifera from mid-Pacific flat-topped seamounts, J. Paleontol., 27, 204-37, 1953.

Henriksen, K., Stipp, S. L. S., and Young, J. R.: Biological control on calcite crystallization: AFM investigation of coccolith polysaccharide function, Am. Mineral., 89, 1709-16, 2004.

Holligan, P. M., Fernández, E., Aiken, J., Balch, W. M., Boyd, P., Burkill, P. H., Jones, H. L., Thiemann, G. J., O’Dea, S. A., and
Newsam, C.: A biogeochemical study of the coccolithophore, Emiliania huxleyi, in the North Atlantic, Global Biogeochem. Cy., 7, 879-900, 1993.

Holzapfel, C., Schäf, W., Marx, M., Vehoff, H., and Mücklich, F.: Interaction of cracks with precipitates and grain boundaries: Understanding crack growth mechanisms through focused ion beam tomography, Scr. Mater., 56, 697-700, 2007.

Inkson, B. J., Mulvihill, M., and Möbus, G.: 3-D determination of grain shape in a FeAl-based nanocomposite by 3D FIB tomography, Scr. Mater., 45, 753-8, 2001.

Kato, M., Ito, T., Aoyama, Y., Sawa, K., Kaneko, T., Kawase, N., and Jinnai, H.: Three-dimensional structural analysis of a block copolymer by Scanning Electron Microscopy combined with a Focused Ion Beam, J. Polym. Sci. Part. B, 45, 677-83, 2007.

Kelm, K., Goetz, A., Sehrbrock, A., Irsen, S., Hoffmann, R., Schmahl, W. W., and Griesshaber, E.: Mosaic Structure in the Spines of Holopneustes porossisimus, Zeitschrift Für Krist, Cryst. Mater., 227, 758-65, 2012.

Kubis, A. J., Shiflet, G. J., Dunn, D. N., and Hull, R.: Focused IonBeam Tomography, Metall Mater. Trans. A, 35, 1935-43, 2004.

Langer, G., Geisen, M., Baumann, K.-H., Kläs, J., Riebesell, U., Thoms, S., and Young, J. R.: Species-specific responses of calcifying algae to changing seawater carbonate chemistry, Geochemistry, Geophys. Geosystems., 7, 1-12, 2006.

Langer, G., Nehrke, G., Probert, I., Ly, J., and Ziveri, P.: Strain-specific responses of Emiliania huxleyi to changing seawater carbonate chemistry, Biogeosciences, 6, 2637-2646, doi:10.5194/bg-6-2637-2009, 2009.

Langer, G., Probert, I., Nehrke, G., and Ziveri, P.: The morphological response of Emiliania huxleyi to seawater carbonate chemistry changes: an inter-strain comparison, J. Nannoplankton Res., 32, 29-34, 2011.

Langer, G., Oetjen, K., and Brenneis, T.: Calcification of Calcidiscus leptoporus under nitrogen and phosphorus limitation, J. Exp. Mar. Biol. Ecol., 413, 131-7, 2012.

Langer, G., Oetjen, K., and Brenneis, T.: On culture artefacts in coccolith morphology, Helgol. Mar. Res., 67, 359-69, 2013 a.

Langer, G., Oetjen, K., and Brenneis, T.: Coccolithophores do not increase particulate carbon production under nutrient limitation: A case study using Emiliania huxleyi (PML B92/11), J. Exp. Mar. Biol. Ecol., 443, 155-61, 2013 b.

Leser, V., Drobne, D., Pipan, Z., Milani, M., and Tatti, F.: Comparison of different preparation methods of biological samples for FIB milling and SEM investigation, J. Microsc., 233, 309-19, 2009.

Menden-Deuer, S. and Lessard, E. J.: Carbon to volume relationships for dinoflagellates, diatoms, and other protist plankton, Limnol. Oceanogr., 45, 569-79, 2000.

Nalla, R. K., Porter, A. E., Daraio, C., Minor, A. M., Radmilovic, V., Stach, E. A., Tomsia, A. P., and Ritchie, R. O.: Ultrastructural examination of dentin using focused ion-beam cross-sectioning and transmission electron microscopy, Micron., 36, 672-80, 2005.

Paasche, E.: Roles of nitrogen and phosphorus in coccolith formation in Emiliania huxleyi (Prymnesiophyceae), Eur. J. Phycol., 33, 33-42, 1998.

Paasche, E.: A review of the coccolithophorid Emiliania huxleyi (Prymnesiophyceae), with particular reference to growth, coccolith formation, and calcification-photosynthesis interactions, Phycologia, 40, 503-29, 2002. 
Phaneuf, M. W.: Applications of focused ion beam microscopy to materials science specimens, Micron., 30, 277-88, 1999.

Ridgwell, A., Schmidt, D. N., Turley, C., Brownlee, C., Maldonado, M. T., Tortell, P., and Young, J. R.: From laboratory manipulations to Earth system models: scaling calcification impacts of ocean acidification, Biogeosciences, 6, 2611-2623, doi:10.5194/bg-6-2611-2009, 2009.

Schmahl, W. W., Griesshaber, E., Merkel, C., Kelm, K., Deuschle, J., Neuser, R. D., ., Goetz, A. J., Sehrbrock, A., and Mader, W.: Hierarchical fibre composite structure and micromechanical properties of phosphatic and calcitic brachiopod shell biomaterials - an overview, Miner. Mag., 72, 541-62, 2008.

Srot, V., Bussmann, B., Salzberger, U., Koch, C. T., and van Aken, P. A.: Linking Microstructure and Nanochemistry in Human Dental Tissues, Microsc. Microanal., 18, 509-23, 2012.

Stoll, H. M. and Schrag, D. P.: Coccolith $\mathrm{Sr} / \mathrm{Ca}$ as a new indicator of coccolithophorid calcification and growth rate. Geochemistry, Geophys. Geosystems., 1, 1-29, 2000.

Thierstein, H. R. and Young, J. R.: Coccolithophores: From Molecular Processes to Global Impact, Berlin Heidelberg New York, Springer-Verlag, 2004.

Uchic, M. D., Groeber, M. A., Dimiduk, D. M., and Simmons, J. P.: 3-D microstructural characterization of nickel superalloys via serial-sectioning using a dual beam FIB-SEM, Scr. Mater, 55, 23-8, 2006.
Williams, R. E. A., Uchic, M., Dimiduk, D., and Fraser, H. L.: Three-Dimensional Reconstruction of Alpha Laths in Alpha/beta Titanium Alloys by Serial Sectioning with a FEI NOVA, Microsc. Microanal., 11, 836-7, 2005.

Young, J. R.: Functions of coccoliths in: Coccolithophores, edited by: Winter, A. and Siesser, G. W., Cambridge, University Press, 63-82, 1994.

Young, J. R. and Henriksen, K.: Biomineralization Within Vesicles: The Calcite of Coccoliths, Rev. Min. Geochem., 54, 189-215, 2003.

Young, J. R. and Ziveri, P.: Calculation of coccolith volume and it use in calibration of carbonate flux estimates, Deep-Sea Res. Pt. II, 47, 1679-700, 2000.

Young, J. R., Didymus, J. M., Bown, P. R., Prins, B., and Mann, S.: Crystal assembly and phylogenetic evolution in heterococcoliths, Nature, 356, 516-8, 1992.

Young, J. R., Davis, S. A., Bown, P. R., and Mann, S.: Coccolith ultrastructure and biomineralisation, J. Struct. Biol., 126, 195215, 1999.

Young, R. J., Dingle, T., Robinsonts, K., and Pugh, P. J. A.: An application of scanned focused ion beam milling to studies on the internal morphology of small arthropods, J. Microsc., 172, 81-8, 1993. 